\title{
O ENSINO DO DESIGN NO AMAZONAS: discursos sobre identidade cultural
}

\author{
Alexandre Santos de Oliveira \\ Faculdade Fucapi \\ olialx@gmail.com \\ Rita Maria de Souza Couto \\ PUC-Rio \\ ricouto@puc-rio.br
}

\begin{abstract}
Resumo: Este trabalho expõe parte dos resultados da pesquisa realizada no âmbito do Programa de Pós-graduação em Design da PUC-Rio - Doutorado e que teve como objetivo propor recomendações para o ensino do design no Amazonas a partir do conceito de identidade cultural. Utilizando-se de uma abordagem qualitativa, através da pesquisa bibliográfica e da técnica do grupo focal, esta comunicação apresenta os conceitos sobre identidade cultural, apresentados pelos docentes em Design, lidos sob uma perspectiva crítica que advém da ideia de emancipação social. Os dados obtidos forneceram subsídios para a indicação de princípios pedagógicos, a serem observados no contexto do ensino do design no Amazonas.
\end{abstract}

Palavras-chave: Ensino do Design, cultura, identidade cultural, Amazonas, Grupo Focal

\begin{abstract}
This paper presents part of the results of research conducted under the PhD. Program in Design at PUC-Rio., and aimed to propose recommendations for design education in the Amazonas from the concept of cultural identity. Using a qualitative approach, through literature and the focus group technique, this communication presents the concepts about cultural identity presented by teachers in Design, read on a critical perspective stemming from the idea of social emancipation. The data provided subsidies for the indication of pedagogical principles to be observed in the context of design education in the Amazonas.
\end{abstract}

Keywords: Design education, culture, cultural identity, Amazonas, Focus Group

\section{INTRODUÇÃO}

Este artigo apresenta os resultados da pesquisa desenvolvida no Programa de Pós-graduação em Design - Doutorado na PUC-Rio. A questão norteadora girou em torno da pergunta sobre quais recomendações, a partir de quais enquadramentos 
teórico-metodológicos, podem ser dados ao ensino do design no Amazonas, visando à compreensão do conceito de identidade cultural.

Procurando responder esta questão o quadro teórico, manuseado no processo de desenvolvimento da pesquisa, tomou como ponto de partida a inter-relação entre design, modernidade e identidade cultural. Esta constatação advém de uma extensa revisão de literatura realizada, em obras publicadas no campo do design com foco no tema da identidade cultural (Moraes, 1999, 2004, 2006; Villas-Boas, 2000a, 2000b, 2002a; Ono, 2006; Queiroz 2005; Queiroz e Niño, 2006a e 2006b) e permitiu entender que a ideia de identidade cultural, apresentava-se com uma categoria que tenderia a promover uma modernidade singular, especialmente nos casos brasileiro e amazônico.

Num segundo momento a investigação teórica procurou compreender, a partir de um referencial ligado à emancipação social (Santos, 2002, 2006a, 2007 e 2008), de que modo as disputas entre regulação e emancipação foram sendo travados no contexto da racionalidade moderna de modo que as energias emancipatórias transformaram-se em energias regulatórias e como este processo, de certa forma, contribui para a reconstrução da ideia de identidade. Tal análise procurou, sempre que possível, identificar interseções que oportunizassem pensar o campo do design de modo geral e o ensino do design de forma específica.

Assim, os conflitos de interesse entre os princípios do mercado, do estado e da comunidade, no âmbito da referida racionalidade, ocasionaram uma crescente transformação da emancipação em regulação. Compreendendo as energias emancipatórias como aquelas que deveriam garantir, no interior da modernidade, um espaço de manejo/manobra/movimentação que, no quadro das disputas entre regulação e emancipação, permitissem pensar as relações sociais em termos mais igualitários.

No entanto, a reflexão teórica indicou que a modernidade, em todo o seu percurso de desenvolvimento, não conseguiu garantir, de forma contínua, um espaço para a emancipação social, e quando tentou fazê-lo, cooptou-a de tal forma que fez desaparecer qualquer possibilidade que não fosse uma emancipação pensada sob os parâmetros da regulação. Assim, a modernidade e as formas de racionalidade por ela produzidas, foram bem sucedidas no cumprimento deste intento por meio de um conjunto de procedimentos e iniciativas, com destaque para a ideia de modernização.

Neste percurso e como fruto do desdobramento teórico, procedeu-se uma análise do conceito de modernização (Santos, 2006; Le Goff, 2003; Faoro, 1992 e 1994 e Bell, 1989), procurando entender esta concepção como consequência do paradigma da modernidade ocidental; considerando as suas implicações para o ensino do design no Brasil e no Amazonas. Para, em seguida, registrar os conceitos surgidos nos grupos focais da discussão sobre identidade cultural desenvolvendo uma compreensão crítica sobre eles.

No que respeita à identidade (Bauman, 2005; Bhabha, 1998; Hall, 2006), tal conceito foi tratado sob um ponto de vista polissêmico por tratar-se de uma construção que se apresenta, ao mesmo tempo, como problema e oportunidade. Um problema porque trata-se de uma formulação que reúne elementos díspares e dicotômicos, reunidos sob um mesmo signo e com o objetivo de criar uma relação de proximidade e vizinhança entre eles. Oportunidade porque esta mesma dicotomia e disparidade favorece, o exercício de uma imaginação criativa necessária à superação 
dos reducionismos conceituais que insistem em reforçar as imposições em detrimento do diálogo.

No plano metodológico, optou-se por uma abordagem qualitativa pois, nesta modalidade de pesquisa, a inquirição, a interpretação e as possibilidades de novas leituras apresentam-se como princípios fundamentais, tanto para aclarar a compreensão sobre o objeto de estudo, como para trazer à luz novas oportunidades para a elucidação do problema. A técnica de Grupo Focal foi utilizada para a realização da empiria sendo que as falas dos docentes que atuam em cursos de design, enquanto informantes da pesquisa, foram analisadas em três etapas, qual seja, aproximação, compreensão e apropriação.

O tratamento e a reflexão sobre os dados oportunizaram a emergência de três polarizações conceituais sobre a ideia de identidade cultural: região, tradição e tradução - comunicação. As conceituações acerca da identidade cultural, tal como apresentadas pelos docentes em design, evocam a reflexão sobre o espaço de onde se fala (a região), sobre o que se está falando (a tradição) e sobre como esta fala é operacionalizada (a comunicação - tradução).

Assim, este trabalho está estruturado em três grandes blocos. No primeiro são apresentados aspectos referentes aos procedimentos metodológicos utilizados no desenvolvimento da pesquisa, com atenção especial para a captação e análise dos discursos produzidos pelos docentes que atuam em cursos de design no Amazonas. No segundo bloco são apresentados, de forma sintética, os resultados obtidos durante o processo de análise dos dados e no último bloco, são apresentadas as conclusões da pesquisa e as oportunidades para trabalhos futuros.

\section{O MÉTODO}

A pergunta sobre quais enquadramentos teórico-metodológicos poderiam ser dados ao ensino do design no Amazonas, visando a compreensão do conceito de identidade cultural, constituiu-se na questão central do estudo. Para responder a esta demanda dois caminhos metodológicos foram traçados. O primeiro consistiu na investigação dos discursos de ordem teórico-conceitual e o segundo tomou como ponto de partida as interrogações sobre como os docentes que atuam em cursos de design no Amazonas, compreendem o conceito de identidade cultural, sendo este 0 aspecto que merecerá destaque neste trabalho.

A abordagem qualitativa norteou o desenvolvimento da investigação. Nesta modalidade de pesquisa cujo objetivo é melhor compreender o comportamento, a experiência, os significados atribuídos, bem como descrever em que consistem estes mesmos significados, nada é trivial (Bogdan \& Biclen, 1994), tudo tem potencial para indicar pistas, visando a compreensão do objeto de estudo e conduzindo à elucidação dos problemas.

\section{Grupo Focal}

No que respeita aos procedimentos técnicos, a utilização do Grupo Focal permitiu a observação direta e a coleta de dados empíricos. O campo é sempre um desafio ao pesquisador qualitativo e não é à toa que, para Gil (2002), a pesquisa de campo caracteriza-se pela aproximação e aprofundamento sobre determinado grupo pesquisado, procurando entender sua constituição e funcionamento.

Para organização do processo de coleta de dados em campo, utilizando a técnica do grupo focal, tomou-se como referência e ponto de partida, a pesquisa 
empreendida por Ribeiro (2008,) que, define o Grupo Focal como uma técnica de coleta de dados por meio de um tópico proposto pelo pesquisador e sob o qual os participantes são convidados a refletir, discutir e externar suas opiniões.

A ênfase na utilização do Grupo Focal, conforme destaca Flick (2009 p. 188), reside na interação que a técnica oportuniza entre os participantes da pesquisa. 0 autor lembra que "a marca que define os grupos focais é o uso explícito da interação do grupo para a produção de dados e insights que seriam menos acessíveis sem a interação".

Além das possibilidades de externalização de opiniões e da interação, por parte dos participantes, outro aspecto assinalado por Fern (2001), no que respeita à aplicação da técnica do grupo focal, é a abertura para comparar os resultados obtidos com o plano teórico sob o qual se está trabalhando. Esses resultados podem, ainda, ser confrontados com as crenças e percepções/predições do pesquisador, através de um processo de triangulação de dados e informações.

\section{0 grupo focal experimental}

Num primeiro momento e a partir das indicações, fornecidas pela literatura (Barbour, 2009, Gatti, 2005, Fern, 2001 e Silverman, 2009), organizou-se um grupo focal em caráter experimental, objetivando testar a pertinência da questão disparadora, verificando sua validade, além de identificar que outros elementos deveriam/poderiam ser agregados para que os resultados e as informações necessárias à elucidação da questão central, pudessem vir à luz durante o processo de discussão.

Os aprendizados obtidos com o grupo focal experimental permitiram uma série de aperfeiçoamentos, tais como: a necessidade de redirecionar e reorganizar a questão disparadora; a urgência em aperfeiçoar e diversificar os materiais de estímulo, objetivando dar mais fluência às discussões e aperfeiçoar os instrumentos de coleta/captação dos dados.

\section{Perfil dos docentes e critérios de seleção}

Os docentes que atuam em cursos de design no Amazonas, constituíram-se nos principais informantes da pesquisa. As seções de grupo focal foram realizadas em duas instituições de ensino superior e participaram um total de 25 (vinte e cinco) docentes. No tocante ao gênero, participaram 11 (onze) docentes do sexo masculino, perfazendo um total de $54 \%$, e 14 (quatorze), do sexo feminino correspondendo a $56 \%$.

O conjunto de informações fornecidas pelo tempo de exercício na função docente foi utilizado como critério de recorte para a leitura dos dados. Esta ação foi necessária pois, no processo de organização dos dados, a extensão e complexidade dos mesmos, requereu o estabelecimento de um critério de seleção que possibilitasse uma leitura possível dos dados e que não comprometesse a reciprocidade dos mesmos, quando comparados com a realidade da qual emergiram. Sendo assim, foram selecionados os docentes que possuíam experiência no exercício do magistério entre seis e 25 (vinte e cinco) anos, perfazendo um percentual de mais de $50 \%$ do total de participantes, ou seja, 14 docentes.

\section{Análise dos dados}

O processo de leitura dos dados foi realizado em três momentos denominamos: aproximação, compreensão e apreensão.

\section{Aproximação}


Na fase de aproximação, foi necessário observar as ideias mais recorrentes, os temas fortes colocados em discussão e as primeiras noções sobre o conceito de identidade cultural, revelado através das falas dos docentes. É certo que esta leitura dos dados foi realizada tanto de modo individualizado como de forma globalizada, ou seja, considerando a fala de todos os participantes em separado e no seu conjunto.

\section{Compreensão}

O momento da compreensão foi se desenvolvendo, tomando como base o inquirir e o escutar. $O$ inquirir, a indagação e a pergunta continuaram sendo o caminho para chegar ao conteúdo. As perguntas, nesta fase de contato com os dados, foram sendo formuladas tomando como base, tanto o corpus teórico, que estava sendo construído para dar suporte à investigação, como a escuta sensível das vozes dos docentes que participaram das seções de grupo focal.

Assim, o duplo movimento de inquirição e escuta oportunizou o aparecimento de diferentes arranjos discursivos. De tais arranjos foram selecionados aqueles que ilustram como as polarizações conceituais foram se organizando ao longo do percurso, dando origem à compreensão dos dados, tal como pode ser observado na Figura 1.

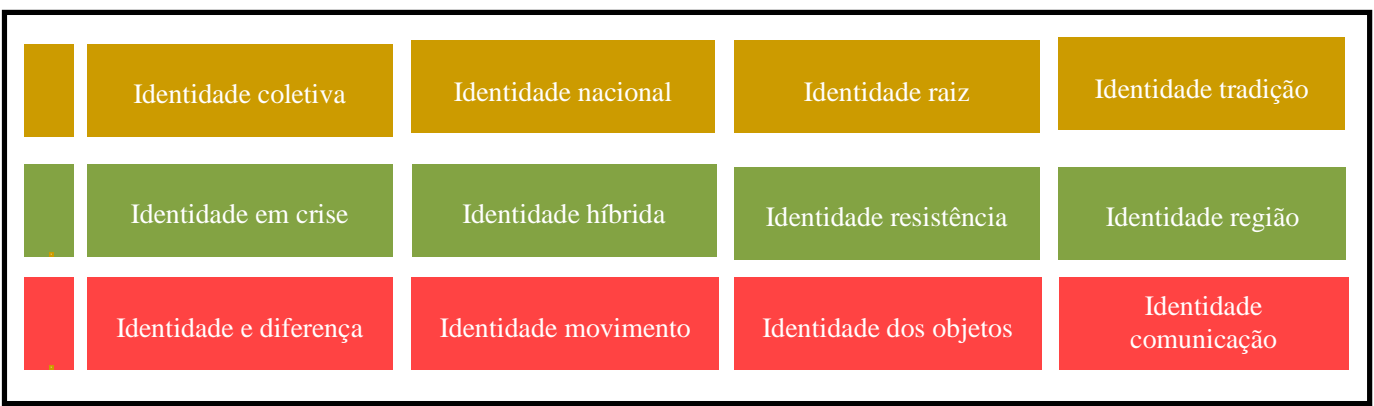

Figura 1 - Arranjos discursivos. Fonte: Elaborado pelo autor

É importante observar que os arranjos foram sendo produzidos, à medida que o esforço por compreender os dados se processava. No entanto, é importante ressaltar que a incompletude dos arranjos induziu a busca por outras formas de organização dos dados e neste processo foram elaborados três núcleos polarizadores, que procuram concentrar os principais conceitos surgidos nos grupos focais, conforme pode ser observado na Figura 9 a seguir.

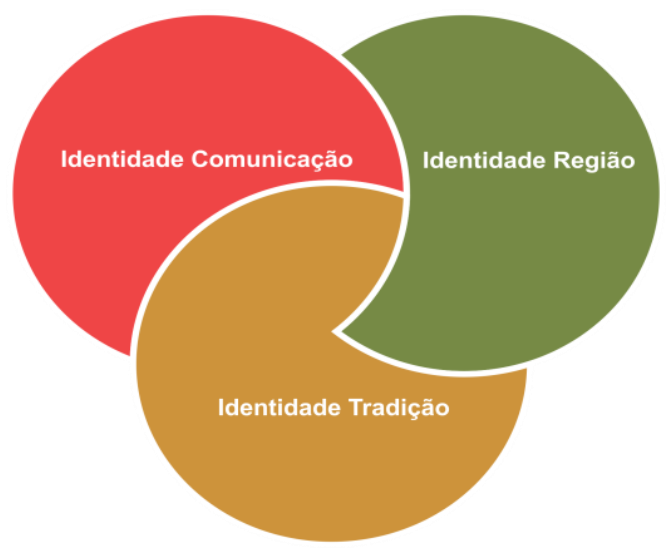

Figura 09 - Síntese das polarizações conceituais. Fonte: Elaborado pelo autor

\section{Apropriação}


A etapa de leitura dos dados denominada de apropriação, objetivou buscar as interconexões possíveis, a partir dos resultados obtidos nos momentos de aproximação e compreensão. Esta busca pelas interconexões centrou-se no aprofundamento das polarizações conceituais, identificadas no momento da compreensão, sendo que o foco residiu, tanto na exploração do potencial criativo dos conceitos e categorias, como no aproveitamento das possibilidades indicadas pela leitura dos dados.

\section{RESULTADOS}

Durante o processo de leitura dos dados obtidos por meio da realização dos grupos focais, foram sendo formuladas as polarizações conceituais região, tradição e comunicação, oriundas dos discursos dos docentes em design cujos resultados são apresentados a seguir.

\section{Região}

Quando interrogados sobre o que entendiam por identidade cultural, o discurso/ideia de região aparece como um recurso explicativo que os docentes lançam mão para nomear como compreendem a identidade cultural. No entanto, e tomando como base tais discursos, é possível observar que a noção de região (Milton Santos, 1998, 2006 e 2008), apesar de concebida como uma unidade aparentemente estável, sedimentada por aspectos de uma similitude territorial, emerge como uma referência incompleta, fruto de uma necessidade de especialização e compartimentalização levada a efeito pela modernidade.

O que parece estar em questão não é a região em si, mas os usos dessa ideia/conceito enquanto expressão de identidade que podem servir, tanto para conformar a fragmentação do lugar e sua fragilização em relação a outras regiões, onde os mecanismos de coesão e de identificação parecem mais sedimentados, quanto podem transformar-se em um lugar de disputas e de contestação que fortaleçam os vínculos locais, dando origem a contratualidades internas mais horizontais, baseadas em normas locais e a serviço de projetos locais.

Outro aspecto que perceptível no discurso dos docentes foi a concepção de região atrelada a elementos étnicos, nomeadamente, a questão indígena. Se por um lado o reconhecimento das identidades de matriz étnica podem ser evocados por conta da relação de temporalidade destes grupos na região, por outro, as discordâncias e inseguranças sobre essa questão ainda perpassam o discurso dos docentes.

No entanto, a questão em aberto não se resume em identificar se a identidade indígena é ou não a identidade da região. $O$ que está em questão, são os processos de apropriação do espaço que, historicamente, oscilaram entre negação e reconhecimento das diversas identidades étnicas, em favor de uma identidade de viés híbrido, mestiço ou miscigenado, ao gosto da forma de racionalidade dominante, que, de certo modo, criou uma atitude de suspeita sobre todas as outras formas de reinvindicação identitária na região.

\section{Tradição}

Durante o processo de análise dos diálogos dos docentes no decorrer dos grupos focais, a ideia de identidade cultural atrelada à perspectiva de manutenção e/ou preservação das tradições (Hobsbawm e Ranger, 2008; Bauman, 2005), 
constituiu-se numa abordagem recorrente entre os docentes, dando origem à polarização conceitual identidade tradição.

As categorizações que foram surgindo, como resultado de uma escuta atenta à fala dos docentes, demonstram esse processo. A tradição apresenta-se como uma formulação emblemática, porque perpassa as demais categorias, a saber: região e comunicação sem, contudo, perder o seu vigor e tônus próprio. Os vínculos entre começo, princípio e essência, como polarizações conceituais explicativas para o termo identidade cultural, atestam a relação entre tradição e origem, presente no discurso dos docentes.

Através do discurso dos docentes em design no Amazonas, é possível dizer que, a identidade tradição pode ser lida como orientada ao futuro e ao progresso por mais que esta constatação possa parecer contraditória. Desta forma, a estratégia de absorção da tradição consiste em estabelecer vínculos porosos entre fixidez e movimento.

A identidade tradição, enquanto uma das opções disponíveis no conjunto das totalidades da racionalidade moderna, passa a ser vista sob a perspectiva da homogeneidade e, dessa forma, as variações e mutações que a tradição possam apresentar, são interpretadas como particularidades que, por conta da estabilidade que as formas de racionalidade atribuem ao todo, não parecem desestabilizar ou comprometer a credibilidade dos discursos sobre a tradição.

\section{Comunicação e Tradução}

A ideia de comunicação, extraída do discurso dos docentes em design no Amazonas, foi analisada por meio da categoria tradução (Bhabha, 1998; Santos, 2008; Benjamin, 2011). Tal categoria pode ser lida a partir de três vertentes: a primeira refere-se aos sujeitos que operam a tradução, ou seja, os docentes em design como tradutores; a segunda, diz respeito ao processo de tradução e a terceira, faz alusão aos resultados ou ao produto da tradução. No percurso das falas, entendidas elas mesmas como tentativas de tradução, os docentes foram apresentando elementos que permitiram ao pesquisador, identificar concepções e métodos enquanto formas de ler a dinâmica processual na qual o fenômeno da identidade está imerso.

Tal constatação conduz à afirmação de que a identidade comunicação e a tradução constituem-se fenômenos análogos, onde a tradução se oferece como caminho e como possibilidade de materialização para a identidade. As pistas fornecidas pelos docentes em design e que permitiriam esta interpretação podem ser percebidas nas seguintes ênfases: expressão, comunicação, transmissão e materialidade, que se constituem ao mesmo tempo em saberes e práticas de tradução.

Todavia, é acertado entender que, tanto o renascer da comunicação tradução, como os processos de transmissão resultantes, precisam ocupar-se também dos elementos que não foram incorporados às estruturas de comunicação e de transmissão consagradas pela modernidade ocidental. Isso demanda dos tradutores a investigação dos elementos intraduzíveis, silenciados, negados e postos à margem dos circuitos hegemônicos, visando dar consecução a processos de tradução, no âmbito do ensino do design no Amazonas, que efetivamente proponham um diálogo mais horizontal entre saberes, práticas, instrumentos e seus produtos, objetivando dar crédito e espaço para a emergência de novos processos de tradução.

Assim, os discursos dos docentes em design que evocam a perspectiva da comunicação - tradução parece responder à necessidade de construção e reconstrução 
de quadros de referência, por meio dos quais é possível movimentar-se na intrincada cadeia sociocultural. Visto desta forma, o ato de comunicar - traduzir pode ser lido como um lugar de fronteira e de passagem, o lugar do acontecer identitário e o espaço por meio do qual a ideia de identidade é forjada, moldada, concretizada e constantemente atualizada.

\section{DISCUSSÃO}

Ao equacionar os objetivos da pesquisa com os achados, ficou evidente que os conceitos de região, tradição e comunicação- tradução, constituem formas e modos através dos quais os docentes em design no Amazonas qualificam a maneira como veem a identidade cultural. Claro que uma leitura como esta só foi possível por conta da crítica à modernidade empreendida através da compreensão sobre como as energias emancipatórias foram sendo transformadas em energias regulatórias, no contexto da modernidade ocidental.

Uma constatação como essa possibilitou pensar, tanto a perspectiva de um ensino do design comprometido com a regulação, como a possibilidade de pensá-lo sob diferentes caminhos, qual sejam, a oportunidade de que a busca por outras formas de pensar, ou seja, a busca por novas racionalidades, possam continuar devolvendo ao campo do design a sua capacidade de indignação, de mudança e de contraponto, isto é, a devolução ao campo do design do seu caráter emancipatório.

Isso porque a ideia de modernização, enquanto corolário do paradigma da modernidade ocidental trouxe implicações para o estabelecimento do ensino do design no Amazonas. Tais causas e interseções caminham desde a reprodução acrítica de modelos externos até o silêncio com relação às especificidades regionais que, os discursos dos docentes, desconstroem ao afirmarem o compromisso com a região, com a tradição e com a comunicação - tradução, enquanto formas de ver, de situar-se e de traduzir, face o presente contínuo imposto tanto pela modernidade como pela modernização.

Da mesma forma que os discursos proferidos apresentam consonâncias, de igual forma mostram-se também, divergentes, provocadores e propositivos, como devem ser as propostas que se apresentam como alternativas às dualidades sufragadas pela modernidade ocidental. $O$ ensino do design no Amazonas reproduz essas dualidades a partir de uma perspectiva quase mimética como bem alertou Dijon de Moraes. No entanto e como o ato de imitar requer dos imitadores um conjunto cada vez mais rebuscado de habilidades, a busca pela imitação enquanto uma das tantas etapas do processo de criação propicia também o inconformismo, reclamam o diálogo, trazem à luz novos desafios, abrem novas perspectivas ao tempo que requisita a emergência de novos modelos, novas formas e fórmulas que, de alguma maneira, redundam em novos aprendizados.

E é precisamente nessa perspectiva que está o fermento capaz de impregnar a teoria e prática no âmbito do ensino do design no Amazonas: o inconformismo que advém do esgotamento dos processos de tradução, calcados em mera reprodução de modelos previamente estabelecidos. Tal perspectiva advém dos discursos proferidos pelos docentes em design no Amazonas que, aos olhos menos avisados, podem parecer senso comum, mas, indicam o impacto de tais ideias no desenvolvimento de princípios teórico-metodológicos que venham ser dados, tanto para a compreensão do conceito de identidade cultural no campo do design, como para fazer com que tais 
princípios cheguem, efetivamente, no dia a dia das salas de aula, se é que esse processo já não se iniciou.

Como contribuição oriunda da presente investigação, foram elaboradas no plano pedagógico, recomendações que podem subsidiar uma maior consistência para o ensino do design no Amazonas, a saber:

1. Para dar conta de um ensino do design culturalmente situado, faz-se necessário empreender imersão no pensamento social na Amazônia, objetivando entender sua dinâmica, a circulação de saberes e ideias que propiciam perceber quais as oportunidades que esses discursos trazem para pensar o ensino do design no Amazonas.

2. É necessário diminuir as distâncias entre atores e práticas de ensino, entre docentes e discentes, entre conhecimento e realidade social, seja ela local, regional ou étnica.

3. Urge investigar como os currículos dos cursos de design no Amazonas tem funcionado como locus de tradução cultural. Como e através de quais mecanismos tais currículos posicionam-se face as questões de identidade cultural? Qual a ênfase desses currículos e como eles impactam nos projetos de final de curso desenvolvidos pelos alunos? Existem trabalhos que poderiam ser identificados como possuindo uma ênfase em identidade cultural? Quais as abordagens? Quais resultados?

4. É urgente entender ainda os modos pelos quais os conhecimentos transitam/movimentam-se nos processo de ensino, de onde vem e para onde são direcionados. De que forma este movimento provê um arcabouço maior de práticas culturais contextualmente situadas no passado da tradição, no presente da modernidade e de igual forma, conectado com o futuro da tecnologia?.

5. Por fim, faz necessário tomar as experiências, sentidos, ideias e vivências dos sujeitos envolvidos nos processos de ensino, ou seja, ouvir o que os tradutores de toda ordem têm a dizer sobre os seus processos de formação e como pensam a inserção política, social e cultural do seu fazer.

Feito isso e orientando-se por e através de tais pressupostos, o ensino do design no Amazonas reunirá as condições necessárias para representar e contribuir com o que a identidade tem de mais elementar e ao mesmo tempo de mais complexo, qual seja, a experiência comum entre as pessoas contribuir, de forma mais efetiva, para fomentar a utopia de uma sociedade construída sob o signo da identidade enquanto igualdade e equidade entre todos.

\section{REFERÊNCIAS}

BARBOUR, R. Grupos Focais. Porto Alegre: Artmed, 2009.

BAUMAN, Z. Identidade: entrevista a Benedetto Vecchi/Zigmunt Bauman. Rio de Janeiro: Jorge Zahar Ed., 2005.

BAUMAN, Z. Identidade: entrevista a Benedetto Vecchi/Zigmunt Bauman. Rio de Janeiro: Jorge Zahar Ed., 2005. 
BELL, D. Las-Contradicciones Culturales Del Capitalismo. México, D.F. Editorial Patria S.A, 1989.

BENJAMIN, W. A tarefa do tradutor. (Die Aufgabe des Übersetzers, Gesammelte Schriften, IV.1, p. 9 -21). (Trad. Maria Filomena Molder.) Texto digitalizado, 13 p. Consulta jan./2011. Disponíuvel em http://www.c-e-m.org/wp-content/uploads/atarefa-do-tradutor.pdf. Acesso em 21.01.2013.

BHABHA. H. K. O local da cultura. Belo Horizonte. Editora da UFMG, 1998.

BOGDAN, R. C.; BIKLEN, S. K. Investigação Qualitativa em Educação: uma introdução à teoria e aos métodos. Porto - Portugal. Porto Editora, 1994.

FAORO, R. A questão nacional: a modernização. Estud. av., São Paulo, v. 6, n. 14, Apr. 1992. Disponível

em

$<$ http://www.scielo.br/scielo.php?script=sci arttext\&pid=S0103-

$40141992000100002 \& \operatorname{lng}=e n \& n r m=i s o>$. Accesso em 31 julho de 2010.

FAORO, R. Existe um pensamento político brasileiro? São Paulo: Ática, 1994.

FERN, E. F. Advanced focus group research. Sage Publications. California, USA, 2001.

FLICK, U. Introdução à coleção pesquisa qualitativa In BARBOUR, Rosaline. Grupo Focais. Porto Alegre: Artmed, 2009a.

GATTI, B. A. Grupo focal na pesquisa em ciências sociais e humanas. Brasília: Líber Livro Editora, 2005.

GIL, A. C. Como elaborar projetos de pesquisa. 4.ed. São Paulo: Atlas, 2002.

HALL, S. A identidade cultural na pós modernidade. 11a Ed. Rio de Janeiro: DP\&A, 2006.

HOBSBAWN, E.; RANGER, Terence. (org). A invenção das tradições. (6a ed.) São Paulo: Paz e Terra, 2008.

LE GOFF, J. História e Memória. Campinas, SP: Editora da UNICAMP, 2003.

MORAES, D. de. Análise do design brasileiro: entre mimese e mestiçagem. São Paulo: Edgard Blucher, 2006.

MORAES, D. de. Limites do design. São Paulo: Studio Nobel, 1999.

MORAES, D. de. Manifesto da razão local: a multiculturalidade como cenário para o design. In_LAGES, V. (et. all.). Territórios em movimento: cultura e identidade como estratégia de inserção competitiva. Rio de Janeiro: Relume Dumará/Brasilia, DF: SEBRAE-NA, 2004.

ONO, M. M. Design e cultura: sintonia essencial. Curitiba: Edição da Autora, 2006.

QUEIROZ. K. G. Design Amazônico: Desafios de sustentabilidade, cultura material e expressão cultural In Ano III, No 7, Julho de 2005. Disponível em https://portal.fucapi.br/tec/imagens/revistas/049 054 design amazonicol SEG.pdf. Acesso em 12.06.2009.

QUEIROZ. K. G.; NIÑO, C. G. R. Design, política e trabalho na diáspora Amazônica: do imaginário regional exotizado ao consumo do imaginário refletido. In__Anais do 70 
Congresso Brasileiro de Pesquisa e Desenvolvimento em Design - P\&D Design Associação de Ensino e Pesquisa de Nível Superior em Design no Brasil; Curitiba; Paraná, 2006a.

QUEIROZ. K. G.; SILVA FREITAS, M. C. da. "Ethos" e "Pathos": A questão da cultura matarial dos povos amazônicos na composição do Design Amazônico. In_Anais do 70 Congresso Brasileiro de Pesquisa e Desenvolvimento em Design - P\&D Design Associação de Ensino e Pesquisa de Nível Superior em Design no Brasil; Curitiba; Paraná, 2006b.

RIBEIRO, F. N. da F. Internet e imagem; representações de jovens universitários. Rio de Janeiro, 2008. Tese (Doutorado em Educação) - Faculdade de Educação, Pontifícia Universidade Católica do Rio de Janeiro.

SANTOS, B. de S. Renovar a teoria critica e reinventar a emancipação social; tradução Mouzar Benedito. SãoPaulo: Boitempo, 2007.

SANTOS, B. de S. Renovar la teoría crítica y reinventar la emancipación social: encuentros en Buenos Aires. Buenos Aires: Consejo Latinoamericano de Ciencias Sociales- CLACSO, 2006a.

SANTOS, B. de S. A crítica da razão indolente: contra o desperdício da experiência, (2 2 ed.). Porto. Afrontamento, 2002.

SANTOS, B. de S. A gramática do tempo: para uma nova cultura política. $2^{a}$ ed. São Paulo: Cortez, 2008.

SANTOS, B. de S. Pela mão de Alice: o social e o político na pós-modernidade. São Paulo: Cortez, 2006.

SANTOS, M. A Natureza do Espaço: Técnica e Tempo, Razão e Emoção. (4a. ed.). São Paulo: Editora da Universidade de São Paulo, 2006

SANTOS, M. Por uma outra globalização: do pensamento único à consciência universal. (17. ed.) Rio de Janeiro: Record, 2008

SANTOS, M. Espaço e sociedade: Ensaios. 2ª ed. Petrópolis: Vozes, 1982.

SILVERMANN, D. Interpretação de dados qualitativos, métodos para análise de entrevistas, textos e interações. Porto Alegre: Artmed, 2009.

VILLAS-BOAS. A Identidade e Cultura. Rio de Janeiro: 2AB, 2002a.

VILLAS-BOAS. A Identidade nacional é invenção. In_Estudos em Design - Anais do 40 Congresso Brasileiro de Pesquisa e Desenvolvimento em Design - P\&D Design Associação de Ensino e Pesquisa de Nível Superior em Design no Brasil; Novo Hamburgo, RS, 2000b.

VILLAS-BOAS. A Por que a identidade nacional voltou a ser uma questão importante. In_Estudos em Design - Anais do 40 Congresso Brasileiro de Pesquisa e Desenvolvimento em Design - P\&D Design - Associação de Ensino e Pesquisa de Nível Superior em Design no Brasil; Novo Hamburgo, RS, 2000a. 